\title{
CONSTITUCIONALIDADE RESTRITIVA À LIBERDADE PELA LEI N. 13.146/2015 NA INCLUSÃO SOCIAL ESCOLAR, COM BASE NA REGRA DA PROPORCIONALIDADE
}

\section{CONSTITUTIONALITY PROVIDER OF FREEDOM UNDER THE LAW N. 13.146/2015 ABOUT THE INCLUSION OF ALL PERSONS IN SOCIAL EDUCATION BASED ON PROPORTIONALITY}

\author{
Rebecka Martins Gomes ${ }^{1}$ \\ Eduardo Teixeira Gomes ${ }^{2}$ \\ Gabriel Ferreira Sartório ${ }^{3}$
}

RESUMO: O presente artigo objetiva analisar a constitucionalidade da medida trazida no art. $28, \mathrm{XI}, \S 1^{\circ}$ da Lei n. 13.146/2015, que prevê a disponibilização gratuita, pelas instituições privadas, de profissionais capacitados no atendimento a alunos com deficiência auditiva ou da fala. No estudo do conflito entre os direitos fundamentais à liberdade e à igualdade, sobretudo no âmbito da medida analisada, farse-á uma breve observação do Estado brasileiro na condição de Estado Democrático de Direito e da Constituição Federal de 1988 em sua adequação no Neoconstitucionalismo. Sustentar-se-á uma estrutura principiológica para os direitos fundamentais com a apresentação de métodos de soluções de conflitos com base em teorias defensoras de um suporte fático amplo, restrições externas e conteúdo essencial restrito para os mesmos. Por último, averiguase-á a constitucionalidade da medida restritiva por meio das três fases da regra da proporcionalidade (adequação, necessidade e proporcionalidade em sentido estrito), resultando na sobressalência da importância da igualdade em detrimento da liberdade no caso.

Palavras-Chave: Direitos fundamentais. Inclusão social. Liberdade. Igualdade. Regra da proporcionalidade.

1 Graduanda em Direito na Faculdade Brasileira (MULTIVIX).E-mail: remartinssDV@, hotmail.com.

2 Doutorando em História Social das Relações Políticas pela Universidade Federal do Espírito Santo (PPGHIS-UFES), professor-formador curso História-EAD (UFES). E-mail: aprendiz.edu@gmail.com

3 Mestre em Direito e Garantias Constitucionais pela Faculdade de Direito de Vitória (FDV), professor de Direito Processual Civil na Faculdade Brasileira (MULTIVIX). E-mail: gfsartorio@hotmail.com. 
ABSTRACT: The article aims to analyze the constitutionality of the rule enacted on the art. 28, XI, §1st of the Law n. 13.146/2015, that sets forth free implementation, by private institutions, of professionals that are trained in the care of students with hearing or speech impairments. In the conflictive weighting between the fundamental rights of freedom and equality, related to the specific rule aforementioned, there will be some consideration about Brazil as a Democratic State and the Federal Constitution of 1988 in its adequacy to Neo-constitutionalism. There will be an advocacy in favor of a structure of principles for fundamental rights in terms of presenting methods of conflict resolution based on theories that have defended a resolution based on a wide leeway for fact analyses, external restrictions and restricted content for themselves. Finally, there will be a scrutiny upon the constitutionality of the rule by means of the three phases of proportionality (adequacy, necessity, and stricto sensu proportionality), resulting in the prevailing of the importance of equality in detriment of freedom in the case.

Keywords: Fundamental rights. Social inclusion. Freedom. Equality. Principle of proportionality.

\section{INTRODUÇÃ̃O}

A inclusão social de minorias é elemento essencial na formação de uma sociedade mais democrática e justa, sendo meio de efetivação dos direitos fundamentais de pessoas que se encontram em situação de hipossuficiência no acesso a oportunidades de seu desenvolvimento na comunidade. Visando corrigir o desnível em tal acesso por parte das pessoas com deficiência, em julho de 2015 foi publicada a Lei n. 13.146 - o Estatuto da Pessoa com Deficiência. Dentre as diversas medidas trazidas que visam promover a igualdade no exercício dos direitos para a pessoa com deficiência está a obrigatoriedade de disponibilização, inclusive pelas instituições privadas, de profissionais especializados no atendimento a alunos com deficiência auditiva ou da fala sem a cobrança de valores adicionais.

A medida de caráter social é instrumento de efetivação do exercício do direito fundamental à igualdade pela pessoa com deficiência, promovendo o desenvolvimento intelectual e moral não só do deficiente físico, mas da sociedade que convive melhor com as necessidades e diversidades apontadas por cada 
um. Porém, restringe a livre iniciativa, expressão do direito fundamental à liberdade possuído pelos proprietários de instituições de ensino privadas, que sofrerão o ônus financeiro causado pela disponibilização dos profissionais especializados.

O peso do significado de um direito fundamental impede o tratamento leviano da relativização dos mesmos. De fato, para que a promoção da igualdade não se torne instrumento de injustiça social, faz-se necessário sondar a legitimidade da restrição provocada pela medida aqui analisada, procurando verificar se o direito fundamental à liberdade não foi violado pelo legislador.

\section{ESTADO DEMOCRÁTICO DE DIREITO E SUAS RESPONSABILIDADES SOCIAIS}

A ideia de quais são as finalidades básicas do Estado perante os indivíduos submetidos à sua soberania mudou com o passar do tempo. Desde o surgimento das Constituições escritas, o Estado adquiriu feições diferentes: Estado Liberal de Direito, Estado Social de Direito e Estado Democrático de Direito.

Emergente nas revoluções inglesas do século XVII, o Estado Liberal consolidou o liberalismo político-jurídico e econômico. Assim, a burguesia enxergou o Estado Absolutista como empecilho à liberdade e ao que consideravam progresso, construindo, após diversas transformações, o Estado Liberal. As Constituições liberais traziam os direitos fundamentais de primeira dimensão, predominantemente civis e políticos (como os direitos à liberdade e à propriedade), objetivando a proteção da autonomia privada do indivíduo por meio de uma conduta omissiva do Estado.

Com o passar do tempo, percebeu-se que o Estado Liberal não intervencionista era omisso na efetivação dos direitos fundamentais das classes sociais desfavorecidas - maior parte da população. Nos séculos XIX e XX eclodiram diversos 
movimentos que objetivavam uma postura mais ativa do Estado - surge, então, o Estado Social. Este, ainda que incentive o desenvolvimento da iniciativa privada, é mais intervencionista e tem como um de seus fundamentos a busca pela justiça social. Trata-se não apenas de liberdade perante o Estado, mas também de liberdade por meio do Estado (SARLET, 2015). As Constituições adotaram os direitos fundamentais de segunda dimensão - direito à saúde, ao trabalho e às denominadas "liberdades sociais".

Porém, tanto Estados Liberais quanto Estados Sociais não foram capazes de garantir uma Democracia Representativa autêntica. O Estado Liberal e o Estado Social focavam na questão de abster-se ou não da interferência em certos âmbitos particulares. Como resposta aos problemas sociais intensificados por tal postura, surge o Estado Democrático de Direito, com novo foco: tão importante quanto sobre o que as decisões políticas deveriam tratar era quem deveria participar delas. Faz-se essencial a participação da maior parte possível do povo na tomada das decisões e de todo o povo no controle destas, dando ênfase à legitimidade e não apenas à legalidade das normas jurídicas. Nesse contexto surgem os direitos fundamentais de terceira dimensão - direito à paz, ao desenvolvimento e à qualidade de vida - e de quarta dimensão - direito à democracia, à informação e ao pluralismo (SARLET, 2015).

Além de constituir-se em Estado Democrático de Direito (art. $1^{\circ}$ ), a Constituição Federal Brasileira de 1988 é neoconstitucionalista, como se vê na extensão de seu rol de direitos e garantias fundamentais e na utilização de princípios como fundamentos da República. O Neoconstitucionalismo (POZZOLO, 1998) ou Constitucionalismo contemporâneo, defende uma leitura do Direito baseada em princípios éticos com força normativa, garantindo-lhes segurança jurídica e efetividade. 


\section{DIREITOS FUNDAMENTAIS: DELIMITAÇÃO CONCEITUAL}

Antes de iniciarmos o estudo sobre o conceito, a estrutura e o conteúdo essencial dos direitos fundamentais é de grande relevância compreender o que significa ser detentor de um "direito".

[...] na maioria dos casos, quando dizemos que alguém tem o 'direito' de fazer alguma coisa, subentendemos que seria errado interferir com a realização daquela ação ou, pelo menos, que necessitamos de razões especiais para justificar qualquer interferência. (DWORKIN, 2007, p. 289).

Portanto, ter um direito a algo significa ter a garantia de que as condutas das outras pessoas deverão ser exercidas nos limites do respeito ao mesmo direito. No caso dos direitos fundamentais, é perceptível que nem na doutrina nem no direito positivado há um consenso sobre sua delimitação conceitual. Há, porém, relevante parte da doutrina que entende os direitos fundamentais como "[...] direitos do ser humano reconhecidos e positivados na esfera do direito constitucional positivo [...]" (SARLET, 2015, p. 29), por isso, alguns preferem utilizar a nomenclatura "direitos humanos fundamentais". Ao postular-se determinado direito do homem na Constituição esta lhe prescreve caráter fundamental e o mesmo passa a compor a base que vinculará a atuação do Estado e de seus poderes.

\subsection{Princípios e regras: estrutura e limitação dos direitos fundamentais}

Os direitos fundamentais podem apresentar-se na forma de princípios ou de regras. Os princípios e as regras são estruturas por meio das quais uma norma jurídica é expressa, sendo classificados mediante diversos critérios utilizados pela doutrina. Para o propósito deste trabalho, importa conceituá-los e diferenciá-los com base na natureza da aplicação dos direitos que garantem. Em primeiro lugar, as regras são aplicáveis no raciocínio tudo-ou-nada: no caso ou a regra é válida, e neste caso sua 
resposta deve ser aceita, ou não é válida, e neste caso não influi na decisão (DWORKIN, 2007). Já os princípios são aplicados de acordo com as condições apresentadas em determinado caso concreto, não perdendo sua validade se não puderam ser aplicados quando em conflito com considerações contrárias.

Os princípios possuem uma dimensão que as regras não têm - a dimensão do peso ou importância. Quando os princípios se intercruzam [...], aquele que vai resolver o conflito tem de levar em conta a força relativa de cada um. (DWORKIN, 2007, p. 42).

Em segundo lugar, como consequência da diferença apresentada acima, os princípios "[...] ordenam que algo seja realizado na maior medida do possível dentro das possibilidades jurídicas e fáticas existentes. Princípios são, por conseguinte, mandamentos de otimização [...]" (ALEXY, 2011, p. 90), garantindo direitos prima facie. De acordo com o autor, as regras ou são satisfeitas, ou não, garantindo, portanto, direitos definitivos.

Acerca da relação entre o direito e seus limites ou restrições, existem duas teorias principais: externa e interna. De acordo com a teoria interna, o limite de um direito é intrínseco ao conteúdo deste, sendo definido prévia e independentemente de colisões com outros direitos. Por outro lado, a teoria externa prevê que o conteúdo de um direito é independente da restrição, que só se dará posteriormente por fatores externos a esse direito. Dessa forma, a restrição não será para o conteúdo do direito, e sim para o seu exercício em determinada situação (DA SILVA, 2010).

Os princípios, por não serem definitivos, estão inevitavelmente suscetíveis a colisões das quais resultarão restrições. Essa realidade é criada pela exigência de conciliação entre os direitos de diversos indivíduos, e também de direitos individuais e interesses coletivos (ALEXY, 2011). Como quase todos os direitos fundamentais encontram-se na forma de princípios, 
entendemos que a teoria externa é, regra geral, a mais adequada na interpretação da aplicação dos direitos fundamentais.

\subsection{Métodos de solução de conflitos entre direito fundamentais}

Como visto, a depender da sua estrutura (de princípio ou regra), os métodos de solução nos casos de conflitos entre direitos fundamentais serão diferenciados. Como as regras enquadram-se no esquema do tudo-ou-nada e garantem direitos definitivos, se duas regras incompatíveis podem ser aplicadas ao mesmo caso, uma delas será necessariamente inválida; no caso de conflitos entre direitos fundamentais, se a incompatibilidade for parcial uma solução possível é o estabelecimento, "[...] em uma das regras, [de] uma cláusula de exceção [...]" (ALEXY, 2011, p. 92) que determina a não abrangência da regra geral em relação a determinado caso e declara a invalidade da parte incompatível, como na hipótese da norma constitucional que postula o direito fundamental à irretroatividade da lei penal, salvo em benefício do réu ( $\left.\operatorname{art} .5^{\circ}, \mathrm{XL}\right)$.

Quando ocorrer colisão entre princípios, utilizar-se-á técnica diversa de solução: não haverá a declaração de invalidade de um deles - ambos continuarão tão válidos quanto antes da colisão. O conflito será solucionado mediante técnica do sopesamento, por meio da qual o aplicador do direito aferirá a força dos princípios analisados no fato, em decorrência da "[...] dimensão do peso [...]" (DWORKIN, 2007, p. 42) de cada um. Assim, uma decisão jurídica determina a prevalência de determinado princípio sobre outro apenas no que se refere às circunstancias de um caso específico. Desse modo,

[...] nosso princípio pode não prevalecer, mas isso não significa que não se trate de um princípio de nosso sistema jurídico, pois em outro caso, quando essas considerações em contrário estiverem ausentes ou tiverem menor força, o princípio poderá ser decisivo. (DWORKIN, 2007, p. 41-42). 
Havendo conflito entre um princípio e uma regra, qual deve ser o método de solução? Se ambos forem constitucionais, a restrição virá por meio de uma "clausula restritiva", que pode ser entendida como "[...] parte de uma norma de direito fundamental completa, que diz como aquilo que, prima facie, é garantido pelo suporte fático do direito fundamental foi ou pode ser restringido". (ALEXY, 2011, p. 286). A solução do conflito é dada pelo próprio constituinte com a criação de tal regra, como no artigo $5^{\circ}$, V, da Constituição Federal de 1988.

Havendo conflito entre princípios constitucionais e regras infraconstitucionais, a solução é diferente. Nesse caso, não há verdadeira colisão entre os dois: a colisão real ter-se-á dado entre o princípio em questão e o princípio que levou à criação da regra, sendo este o que prevaleceu em um sopesamento feito pelo legislador (DA SILVA, 2010). A regra simplesmente enunciará a restrição resultante do sopesamento.

\subsection{Conteúdo essencial e suporte fático}

Conforme Virgílio Afonso da Silva (2010, p. 74), suporte fático, no âmbito do direito constitucional brasileiro, é o conjunto de "[...] elementos que, quando preenchidos, dão ensejo à realização do preceito da norma [...]". Para o autor, os componentes do suporte fático são: âmbito de proteção (estados e condutas protegidos por um direito fundamental) e intervenção estatal não fundamentada constitucionalmente (ou também, para nós, uma intervenção privada não fundamentada constitucionalmente). "Uma norma somente pode ser uma restrição a um direito constitucional se ela for compatível com a Constituição." (ALEXY, 2011, p. 281).

A depender da teoria, o suporte fático pode ser considerado amplo ou restrito. Este último não inclui previamente determinados estados e condutas no âmbito de proteção de uma norma, o que é uma estratégia perigosa por dificultar ou im- 
possibilitar a atualização do âmbito de proteção dos direitos fundamentais e nem sempre estar acompanhada dos critérios que fundamentarão a exclusão de condutas deste; o suporte fático amplo, por sua vez, considera abarcado pelo âmbito toda conduta ou estado de coisas que, isoladamente analisado, esteja incluso na área temática de um direito fundamental (DA SILVA, 2010). Tal teoria admite a possibilidade de colisões entre direitos fundamentais, assentando que nem toda restrição ao exercício de um direito fundamental violará seu conteúdo, desde que fundamentada constitucionalmente. Há alguma parte do conteúdo de um direito fundamental que sempre deva permanecer? Pode nada sobrar de seu exercício sem que seu "conteúdo essencial” seja violado?

As teorias defensoras de conteúdos essenciais absolutos para direitos fundamentais afirmam a existência de um núcleo essencial com limites instransponíveis por quaisquer intervenções restritivas (DA SILVA, 2010). Exemplificando, se partirmos do pressuposto de que o conteúdo essencial do direito fundamental à liberdade considera intransponível a liberdade de contratar fundamentada inclusive em discriminações físicas, será inconstitucional a medida restritiva que obriga as instituições de ensino privadas a fornecerem professores especializados para a educação de deficientes auditivos sem cobrar valores adicionais destes, pois o conteúdo essencial do direito fundamental foi violado. Contudo, tal teoria também é questionada pela dificuldade em se delimitar previamente uma definição justa e socialmente atualizada do conteúdo de um direito fundamental.

Em sentido contrário, as teorias relativistas para o conteúdo essencial dos direitos fundamentais alegam que será adequado declará-lo conforme as circunstâncias de cada caso concreto. A teoria relativista mais utilizada - e adotada neste trabalho - é a que considera como conteúdo essencial de um direito funda- 
mental o produto da aplicação da regra da proporcionalidade, afirmando que restrições a direitos fundamentais que passem no teste da proporcionalidade não afetam o conteúdo essencial dos direitos restringidos (DA SILVA, 2010). Parece-nos a mais adequada, pois evita a limitação discricionária e definitiva do conteúdo essencial do direito fundamental e permite seu exercício o máximo possível no caso concreto, o que é próprio dos direitos fundamentais como mandamentos de otimização.

\section{ESTATUTO DA PESSOA COM DEFICIÊNCIA E CONFLITO ENTRE DIREITOS FUNDAMENTAIS}

A Lei n. 13.146/2015 institui a Lei Brasileira de Inclusão da Pessoa com Deficiência (Estatuto da Pessoa com Deficiência). De acordo com o caput de seu art. $1^{\circ}$, tem a finalidade de "[...] assegurar e [...] promover, em condições de igualdade, o exercício dos direitos e das liberdades fundamentais por pessoa com deficiência, visando à sua inclusão social e cidadania.” (BRASIL, 2015). Percebe-se que restrições promovidas pelo Estatuto são baseadas em argumentos de princípio - pois visam o estabelecimento de um direito individual, não sendo apenas padrões que assegurarão uma situação social considerada desejável, mas exigências de justiça ou equidade (DWORKIN, 2007) e devendo ser respeitadas em face da "[...] responsabilidade comunitária dos indivíduos". (SARLET, 2015, p. 152). Visando concretizar o direito à igualdade material no que tange ao acesso à educação da pessoa com deficiência, o Estatuto dispõe em seu art. 28, inciso XI e no $\S 1^{\circ}$, in verbis:

Art. 28. Incumbe ao poder público assegurar, criar, desenvolver, implementar, incentivar, acompanhar e avaliar: [...] XI-formação e disponibilização de professores para o atendimento educacional especializado, de tradutores e intérpretes da Libras, de guias intérpretes e de profissionais de apoio; [...] $\S 1^{\circ}$ Às instituições privadas, de qualquer 
nível e modalidade de ensino, aplica-se obrigatoriamente o disposto nos incisos I, II, III, V, VII, VIII, IX, X, XI, XII, XIII, XIV, XV, XVI, XVII e XVIII do caput deste artigo, sendo vedada a cobrança de valores adicionais de qualquer natureza em suas mensalidades, anuidades e matrículas no cumprimento dessas determinações. (BRASIL, 2015).

Poder-se-ia argumentar que o artigo acima gera um conflito entre a regra direcionada às instituições privadas de ensino e o princípio constitucional que garante o direito à livre iniciativa (art. $1^{\circ}$, IV e art. $170 \mathrm{c} / \mathrm{c}$ art. $5^{\circ}, \S 2^{\circ}$ ). Na verdade, entendemos que o conflito ocorreu entre o direito fundamental à igualdade (de acesso à educação) e o direito fundamental à livre iniciativa (decorrente do princípio fundamental que a garante), sendo a referida regra (que obriga uma instituição privada a fornecer tradutores e interpretes da Libras $^{4}$ sem que esta exija valores adicionais) um padrão que enuncia a restrição resultante do sopesamento feito pelo legislador. Talvez o legislador nem tenha desenvolvido previamente uma teoria que enxergasse na regra criada a solução de um conflito entre os princípios referidos, mas a realidade é que tal conflito pode ser percebido. Logo, seria a restrição escolhida fundamentada constitucionalmente? Em um sopesamento entre ambos os princípios no caso analisado, deveria o direito à igualdade prevalecer, como exposto pela regra? É o que averiguaremos a seguir.

\subsection{A regra da proporcionalidade}

A regra (ou teste) da proporcionalidade é utilizada para averiguar a fundamentação constitucional de restrições a direitos fundamentais. Não faz sentido aplicá-la se considerarmos que direitos fundamentais possuem suporte fático restrito, limites imanentes (teoria interna) ou conteúdo essencial absoluto, já que esse mesmo conteúdo estaria pré-definido, não admitindo condutas e posições que estejam fora dos limites estabelecidos

4 Linguagem Brasileira de Sinais. 
(DA SILVA, 2010).

Porém, partindo do pressuposto de que direitos fundamentais possuem suporte fático amplo, conteúdo distinto de limitações posteriores (teoria externa) e núcleo essencial relativo, adotamos a aplicação da regra da proporcionalidade como método pelo qual descobriremos se determinada restrição é constitucional, ou seja, se não implica violação do conteúdo essencial do direito fundamental restringido. De acordo com Alexy (2011), a aplicação da regra da proporcionalidade é subdividida em três fases subsequentes: adequação, necessidade e proporcionalidade em sentido estrito. $\mathrm{Na}$ análise, as condições fáticas, que "[...] dizem respeito às medidas concretas que podem ser utilizadas [...]" (DA SILVA, 2002, p. 44) para a realização do direito fundamental serão consideradas sobretudo quando analisadas a adequação e a necessidade da medida restritiva; o campo das possibilidades jurídicas será enfrentado na aplicação da proporcionalidade em sentido estrito, quando contrapostos os princípios em questão (ALEXY, 2011).

\subsubsection{Adequação}

Primeiramente, deve-se averiguar simplesmente se a medida adotada é compatível com a finalidade almejada, ou seja, se é apta para promover ou impulsionar os resultados pretendidos. Para ser considerada adequada, a medida deve estar de acordo com o princípio da razoabilidade garantido pelo devido processo substancial (substantive due process). Encontramos essa ideia no trecho a seguir, extraído da decisão da Suprema Corte dos Estados Unidos no caso Lochner v. New York: "O ato [estatal] deve ter uma relação mais direta, como meio para um fim, e o fim, por sua vez, deve ser apropriado e legítimo, antes que se considere válido um ato que interfira no direito geral de um indivíduo [...]" (USA, 1905, tradução nossa).

Indagamos se a medida tomada no art. $28, \mathrm{XI}, \S 1^{\circ}$ do Es- 
tatuto da Pessoa com Deficiência é adequada para fomentar o objetivo pretendido e se esse objetivo é legítimo. Ora, como exposto, a medida visa promover em condições de igualdade o acesso de alunos com deficiências da fala ou auditivas à educação. A legitimidade do objetivo é clara: em uma República que tem por princípio fundamental a dignidade da pessoa humana, privar um indivíduo de ter acesso ao seu pleno desenvolvimento intelectual e psíquico em razão de deficiências físicas seria, no mínimo, ignorar um pilar de nossa organização social.

A legitimidade da medida estudada não decorre de um simples ato de caridade do Estado ou de empresas particulares, antes se constitui em um direito daquele que é pessoa humana com direitos fundamentais. Todos os dias as barreiras naturais da deficiência física são reforçadas por um sistema educacional que se mostra despreparado e moroso no que tange ao empenho para mudanças efetivas que propiciem um atendimento realmente adaptado ao ser humano portador de deficiências auditivas ou de distúrbios da fala.

Como seria possível haver transmissão de informações se não houver comunicação? A presença de tradutores e intérpretes da Libras é meio essencial para que o ensino seja fornecido de forma eficiente àqueles que possuem impossibilidades físicas de ouvir ou de falar. A Convenção Internacional sobre os Direitos das Pessoas com Deficiências, que passou a ter força de emenda constitucional em 2009, demonstra sua preocupação na adequação da forma de ensino às necessidades do aluno quando prevê que:

[...] os Estados Partes tomarão medidas apropriadas, incluindo: [...] c) Garantia de que a educação de pessoas, em particular crianças cegas, surdocegas e surdas, seja ministrada nas línguas e nos modos e meios de comunicação mais adequados ao indivíduo e em ambientes que favoreçam ao máximo seu desenvolvimento acadêmico e social. (BRASIL, 2009). 
Se a mensagem não for transmitida de maneira adaptada às capacidades do receptor, não há comunicação, muito menos ensino. $\mathrm{O}$ atendimento educacional especializado é requisito básico da inclusão escolar, através do qual o aluno deixa de ser tratado como algo e passa a ser visto como alguém. Logo, a medida restritiva aqui analisada é mais do que coerente, razoável, adequada e legítima.

\subsubsection{Necessidade}

Em segundo lugar, caso não seja considerada inadequada, a medida restritiva deve ser necessária se comparada a outras medidas estatais que poderiam ser tomadas:

Um ato estatal que limita um direito fundamental é somente necessário caso a realização do objetivo perseguido não possa ser promovida, com a mesma intensidade, por meio de outro ato que limite, em menor medida, o direito fundamental atingido. (DA SILVA, 2002, p. 38, grifo nosso).

Alguns autores defendem a opção pela medida menos restritiva (ou menos gravosa) como, em qualquer caso, a mais adequada ao exame da necessidade (ALEXY, 2011), visto que a promoção do princípio não-restringido já foi atestada na fase da adequação. Na verdade, caso a medida mais restritiva seja mais eficiente em promover o resultado visado será considerada necessária e apta à aplicação da terceira fase da regra da proporcionalidade. Segundo Virgílio Afonso da Silva (2010), isso ocorre por dois motivos principais:

a. se a medida escolhida sempre tivesse que ser a menos restritiva do direito atingido significaria a exigência constante de uma posição omissa do Estado, ainda que a realização do resultado pretendido e fundamentado no princípio não restringido fosse de alta importância;

b. Como visto, princípios são mandamentos de otimização, devendo ser realizados o máximo possível diante das 
condições fáticas e jurídicas existentes. Considerando o campo das condições fáticas, a medida menos restritiva deve ser a privilegiada quando for tão eficiente quanto a medida mais restritiva. Porém, a máxima realização dos princípios exige concomitantemente a observância das possibilidades jurídicas que serão enfrentadas através do sopesamento (ALEXY, 2011), o que justificará a importância da realização do princípio prevalecente e nos faz optar definitivamente pela medida mais eficiente em face da menos gravosa.

Nesse ponto, questionamos se há medidas restritivas tão eficientes quanto a prescrita pelo art. 28 da Lei n. 13.146/2015, mas que restrinjam menos o direito à livre iniciativa do proprietário da instituição de ensino privada. Salienta-se a comparação entre a medida analisada e "outras alternativas [...], e não com todas as medidas possíveis e imagináveis entre si". (DA SILVA, 2010, p. 173).

É difícil encontrar medida tão eficiente à inclusão do deficiente auditivo ou da fala quanto a adequação da linguagem à capacidade comunicativa deste. Ir por outro caminho poderia ser como lecionar em mandarim em uma escola brasileira. De fato, vedar a cobrança de valores adicionais ao cliente com deficiência pelo fornecimento de profissionais especializados gera um ônus financeiro não pretendido pelo empresário que presta o serviço da educação; por outro lado, fazer com que o cliente pague a mais pelo mesmo serviço fornecido a outro com capacidades físicas diferentes significa discriminá-lo negativamente por quem ele é.

Em busca de uma medida menos gravosa alguém poderia propor o redirecionamento do ônus financeiro ao Estado. Deve-se, contudo, atentar ao fato de que o direito restringido, por mais que comumente chamado de "direito à livre iniciativa", consiste na verdade em um direito decorrente da norma consti- 
tucional que preconiza a República Federativa do Brasil como um Estado Democrático de Direito e tem como um de seus fundamentos os "valores sociais do trabalho e da livre iniciativa" (art. $\left.1^{\circ}, I V\right)$. Portanto, tal direito apresenta uma prévia restrição diretamente constitucional, que é a condição de ser interpretado de acordo com seu valor social. É uma hipótese em que se estabelece algumas premissas " [...] a partir do teor literal da Constituição, acerca da aplicação das disposições constitucionais em questão". (ALEXY, 2011, p. 165). Não se consiste em agravar o direito além do necessário e sim em aplicá-lo de acordo com a restrição constitucional. Por fim, em julgamento recente do STF, o ministro Edson Fachin, ressaltou que:

[...] não obstante o serviço público de educação ser livre à iniciativa privada, ou seja, independentemente de concessão ou permissão, isso não significa que os agentes econômicos que o prestam o possam fazê-lo ilimitadamente ou sem responsabilidade [...] Em suma: à escola não é dado escolher, segregar, separar, mas é seu dever ensinar, incluir, conviver. (BRASIL, 2015).

Sendo assim, a medida analisada é considerada necessária, e apta a ser submetida à terceira etapa da regra da proporcionalidade.

\subsubsection{Proporcionalidade em sentido estrito}

A terceira e última fase da regra da proporcionalidade consiste na aplicação da mencionada técnica do sopesamento. $\mathrm{O}$ aplicador do direito, ao sopesar os princípios, exercerá a ponderação da dimensão do peso de cada um destes, a fim de "[...] evitar que medidas estatais, embora adequadas e necessárias, restrinjam direitos fundamentais além daquilo que a realização do objetivo perseguido seja capaz de justificar". (DA SILVA, 2010, p. 175). O sopesamento sempre deve observar a seguinte regra: "Quanto maior for o grau de não-satisfação ou de afetação de um princípio, tanto maior terá que ser a importância da 
satisfação do outro". (ALEXY, 2011, p. 167).

A utilização da argumentação jurídica na fundamentação da escolha pelo princípio prevalecente é pressuposto para que o sopesamento não seja entendido como mero instrumento de arbitrariedade. Quando houver conflito entre direitos fundamentais, o aplicador deve valer-se do "[...] principio da concordância prática ou da harmonização, em busca do verdadeiro significado da norma e da harmonia do texto constitucional com suas finalidades [...]" (MORAES, 2003, p. 46). É nosso trabalho, então, ponderar qual princípio (igualdade ou liberdade) deveria prevalecer no caso da restrição ora aferida.

\subsubsection{Liberdade versus igualdade}

Alexy (2011) afirma que o direito geral de liberdade abrange a liberdade de escolha do que fazer ou deixar de fazer, sendo um dos componentes necessários da dignidade da pessoa humana e coexistindo com outros princípios materiais que também são condições imprescindíveis desta. Isso faz com que a liberdade não tenha um peso supremo em relação aos outros valores materiais, dentre eles a igualdade, e leva à exigência do sopesamento no caso concreto.

Dworkin propõe a existência de dois conceitos de liberdade: a liberdade como licença e a liberdade como independência. Segundo o autor, a liberdade como licença consiste no “[...] grau em que uma pessoa está livre das restrições sociais ou jurídicas para fazer o que tenha vontade [...]", diferentemente da liberdade como independência, que é caracterizada como "[...] o status de uma pessoa como independente e igual e não como subserviente." (DWORKIN, 2007, p. 404). A violação da liberdade como independência não pode ser justificada pela preponderância de outros princípios no caso concreto, pois isso seria considerar um grupo de indivíduos moralmente inferior a outro, atentando contra a dignidade da pessoa huma- 
na. Todavia, o mesmo não ocorre sempre que uma lei diminuir o campo de abrangência da liberdade como licença restringindo-a, pois a proteção do valor concorrente ao restringido foi considerada mais adequada à concretização da justiça. "Liberdade, em seu sentido original, significa liberdade em face das restrições." (MILL, 1981 [1824], p. 326, tradução nossa).

A medida governamental estudada nesta pesquisa restringe a liberdade do proprietário da instituição de ensino em prol da concretização do direito fundamental à igualdade. Para que tal restrição passe pelo teste da proporcionalidade em sua última fase (proporcionalidade em sentido estrito), dois desafios precisam ser superados: em primeiro lugar, é necessário verificar se foi respeitada a liberdade como independência daquele que teve sua liberdade restringida; em segundo lugar, deve-se encontrar a fundamentação constitucional pela qual a concretização do princípio da igualdade teve um peso maior de importância do que o princípio da liberdade.

Em relação ao primeiro desafio, o proprietário da instituição privada não teve sua liberdade como independência violada, visto que não foi considerado pelo Estado como alguém moralmente inferior ao aluno e que não tivesse capacidade intelectual e política de opinar nas decisões estatais que limitarão sua liberdade. Se assim não fosse, sequer haveria o cuidado de averiguar a constitucionalidade da medida restritiva de seu direito à liberdade.

O segundo desafio é mais trabalhoso. É pacífico na doutrina constitucional que o direito fundamental à igualdade, nos termos do que é justo, deve ser entendido como a garantia de tratamento igual para aqueles que estejam em condições iguais e de tratamento desigual para os que se encontrarem em condições de desigualdade (ARISTÓTELES, 1999). Alexy (2011) propõe que desse entendimento decorre que o direito de tratamento desigual existe apenas quando houver uma razão sufi- 
ciente para esse tratamento.

Convergindo com esse entendimento, Dworkin apresenta duas dimensões do direito à igualdade: o direito à igual tratamento (equal treatment) e o direito a ser tratado como igual (treatment as an equal). Respectivamente, dizem respeito "[...] à igual distribuição de bens e oportunidades entre as pessoas [e] [...] à igual consideração e respeito na decisão política sobre como tais bens e oportunidades serão distribuídos". (DWORKIN, 2007, p. 420). O direito à igual tratamento só será necessário se decorrer, no caso específico, do direito ao tratamento como igual.

No caso da restrição explorada neste trabalho, o proprietário da instituição privada foi tratado como igual, já que sua posição como sujeito de direitos e deveres na organização social foi considerada e respeitada, o que se pode deduzir pelos mesmos motivos demonstrados na averiguação da preservação de sua liberdade como licença. A necessidade de concretização da igualdade fática (ou material), caracterizada por um conjunto de fatores conducentes à igualdade de oportunidades na realização dos direitos fundamentais justifica discriminações afirmativas, isto é, tratamentos diferenciados para quem se encontra em posição desigual e inferior de acesso à concretização de seus direitos. $\mathrm{O}$ aluno com deficiência auditiva ou da fala possui formalmente o mesmo direito fundamental à educação que qualquer outro aluno. Porém, como demonstrado no exame da necessidade, esse acesso não será realizado na prática se não lhe forem conferidos meios que compensem sua posição originária de desigualdade, como a disponibilidade do interprete de Libras e de profissionais especializados.

Poderiam ser apontados diversos motivos que fundamentam a sobrepujança do peso do direito à igualdade em relação ao direito à liberdade na medida restritiva estudada, mas é imprescindível que tais motivos sejam constitucionais. Primeiramente, a Constituição Federal Brasileira dispõe como um dos 
objetivos fundamentais da República Federativa do Brasil a construção de uma sociedade livre, justa e solidária (art. $3^{\circ}$, I). A liberdade geral, como ideia norteadora da luta por uma sociedade apta à promoção do desenvolvimento humano, não será satisfeita se não for tratada como direito de todos.

Manter um ser humano, por razões de suas debilidades físicas, em uma situação que lhe impeça de ter acesso aos fenômenos sociais que são trabalhados no ambiente escolar é encarcera-lo em prisões invisíveis que limitam arbitrariamente seu poder de escolha. A garantia de liberdade apenas a um grupo socialmente favorecido não caracteriza uma sociedade livre.

Em segundo lugar, os danos que a segregação educacional traz à sociedade são tão exorbitantes que não se pode falar em violação exercida pelo art. $28, \mathrm{XI}, \S 1^{\circ}$, da Lei n. 13.146/2015 à liberdade individual. Segundo o princípio do dano, Stuart Mill afirma que

[...] o único propósito de se exercer legitimamente o poder sobre qualquer membro de uma comunidade civilizada, contra a sua vontade, é evitar danos aos demais. [...] Cada um que recebe a proteção da sociedade deve um retorno a esse beneficio, $\mathrm{e}$ o fato de viver em sociedade torna indispensável que cada um esteja sujeito a observar certa linha de conduta em respeito aos demais. (MILL, 2008, p. 14,43, tradução nossa).

A educação, além de qualificar o ser humano para o trabalho e ser meio de desenvolvimento das interações interpessoais, é instrumento de formação da verdadeira democracia, visto que através dela os indivíduos adquirem consciência das transformações sociais que os cercam e aprendem a posicionar-se criticamente sobre tais fenômenos, proporcionando o desenvolvimento de um povo politicamente pluralista - outro objetivo fundamental da Republica Federativa do Brasil (art. $1, \mathrm{~V}, \mathrm{CF} / 88$ ). Dessarte, não se pode ignorar que a construção de uma sociedade igualitária favorece a todos, sendo, em contrapartida, dever não exclusivo do Estado a sua promoção. 
A quem presta serviço à igualdade? A menção aos beneficiários da igualdade [...] não estaria completa se não abarcasse, além dos particularmente beneficiados, todos nós, que temos direito de conviver com nossos semelhantes/ diferentes e partilhar das experiências da diversidade, em espírito democrático (participativo) e solidário. [...] Chega-se a uma resposta majoritária à questão contramajoritária da discriminação positiva: um preço justo a pagar por todos os que não se encontram em situação de vulnerabilidade, mas que talvez se beneficiam [...] de vantagens sociais e certamente têm [...] uma responsabilidade social compartilhada de "construir uma sociedade livre, justa e solidária" (Constituição brasileira, art. $3^{\circ}$, I). (ROTHEMBURG, 2008, p. 78,79).

Mediante o exposto neste tópico, depreende-se que a medida restritiva emitida pelo art. 28, XI, $\S 1^{\circ}$, da Lei n. 13.146/2015, também não é derrubada no exame da proporcionalidade em sentido estrito. Findo o teste da proporcionalidade, fica exposta a constitucionalidade de tal restrição ao direito fundamental à livre iniciativa para que se alcance a promoção do direito à igualdade no acesso à educação para deficientes auditivos ou com distúrbio da fala.

\section{CONCLUSÃO}

Conclui-se que a medida expressa no art. 28 da Lei n. 13.146/2015 (Estatuto da Pessoa com Deficiência), apesar de restringir o direito fundamental à liberdade dos proprietários de instituições privadas de ensino, não o viola, por ser fundamentada constitucionalmente e partindo dos pressupostos de que direitos fundamentais possuem conteúdos essenciais relativos e são, em sua maioria, princípios.

Tal fundamentação constitucional foi aferida pela aplicação da regra da proporcionalidade, com suas três fases. Na fase da adequação, a medida demonstrou-se apta para perseguir o fim atingido - o acesso dos deficientes auditivos ou com distúrbios da fala à educação. A medida também foi aprovada na análise de sua necessidade, na segunda fase, visto que, dentre as alter- 
nativas analisadas, não foram encontradas medidas restritivas tão eficientes e que simultaneamente restringissem menos o direito à livre iniciativa.

$\mathrm{Na}$ última fase, averiguou-se que o princípio que garante o direito fundamental à igualdade do aluno com deficiência tem no caso maior peso de importância que o direito fundamental à liberdade dos proprietários das instituições de ensino privadas se fizermos uma analise sob a ótica constitucional, considerando que a livre iniciativa é condicionada a seu valor social e que a construção de uma sociedade livre, justa e solidária constitui um dos objetivos fundamentais da República Federativa do Brasil.

O Estado deve garantir a liberdade coadunada com o desenvolvimento humano, obtendo resultados positivos na construção de uma sociedade mais justa e consciente da importância da participação social - inclusive das minorias - na formação de uma democracia efetiva. Por fim, compreende-se que uma sociedade igualitária só é alcançada se todos forem tratados levando em consideração suas condições originárias de igualdade ou desigualdade, o que requererá, em determinados casos, o fomento de políticas que promovam o desenvolvimento de grupos desfavorecidos na satisfação de seus direitos fundamentais. A efetivação dessa igualdade não pode sucumbir ante os interesses individuais que sejam contrários à ordem constitucional.

\section{REFERÊNCIAS}

ALEXY, Robert. Teoria dos direitos fundamentais. Tradução: Virgílio Afonso da Silva. 2. ed. São Paulo: Malheiros, 2011.

ARISTÓTELES. Politics. Kitchener: Batoche Books, 1999. Disponível em: <https://socserv2.socsci.mcmaster.ca/econ/ugcm/3113/aristotle/Politics.pdf>. Acesso em: 17 maio 2017.

BRASIL. Constituição (1988). Constituição da República Federativa do Brasil. Brasília, DF, 5 out. 1988. Disponível em: <http://www.planalto.gov.br/ccivil_03/constituicao/constituicaocompilado.htm>. Acesso em: 8 ago. 2016.

. Decreto Lei n. 6.949, de 25 de agosto de 2009. Promulga a Convenção Internacional sobre os Direitos das Pessoas com Deficiência e seu Protocolo Facultativo. 
Brasília, DF, 25 ago. 2009. Disponível em: <http://www.planalto.gov.br/ccivil_03/_ Ato2007-2010/2009/Decreto/D6949.htm>. Acesso em: 29 maio 2017.

. Lei n. 13.146, de 6 de julho de 2015. Institui a Lei Brasileira de Inclusão da Pessoa com Deficiência. Brasília, DF, 7 jul. 2015. Disponível em: $<$ http://pesquisa. in.gov.br/imprensa/jsp/visualiza/index.jsp?data $=07 / 07 / 2015 \&$ jornal $=1 \&$ pagina $=2 \&$ totalArquivos $=72>$. Acesso em: 8 ago. 2016.

. Supremo Tribunal Federal. Decisão Monocrática. Medida cautelar na Ação Direta de Inconstitucionalidade n. 5357. Relator: Ministro Edson Fachin. Pesquisa de Jurisprudência, Acordãos, 18 nov 2015. Disponível em: <http://www.stf.jus.br/ portal/jurisprudencia/listarJurisprudencia.asp?s $1=\% 285357 \% 2 \mathrm{ENUME} \% 2 \mathrm{E}+\mathrm{OU}-$ $+5357 \% 2 \mathrm{EACMS} \% 2 \mathrm{E} \% 29 \&$ base=baseAcordaos\&url=http://tinyurl.com/hghv2pv $>$. Acesso em: 8 fev. 2017.

DALLARI, Dalmo de Abreu. Elementos de teoria geral do estado. 25. ed. São Paulo: Saraiva, 2005.

DA SILVA, Virgílio Afonso. Direitos fundamentais: conteúdo essencial, restrições e eficácia. 2. ed. São Paulo: Malheiros, 2010.

O proporcional e o razoável. Revista dos Tribunais. São Paulo n. 798, p. 23-50, 2002. Disponível em: $<$ http://constituicao.direito.usp.br/wp-content/uploads/2002-RT798-Proporcionalidade.pdf $>$. Acesso em: 27 maio 2017.

DWORKIN, Ronald. Levando os direitos a sério. Tradução: Nelson Boeira. 2 ed. São Paulo: Martins Fontes, 2007.

MILL, John Stuart. On Liberty and Other Essays. Nova Iorque: Oxford, 2008. . [1824] Autobiography and literary essays. Routdlege: Oxford, 1981.

MORAES, Alexandre de. Direitos humanos fundamentais: teoria geral, comentários aos arts. $1^{\circ}$ a $5^{\circ}$ da Constituição da República Federativa do Brasil, doutrina e jurisprudência. 5. ed. São Paulo: Atlas, 2003.

POZZOLO, Suzanna. Neoconstitucionalismo y especificidade de la interpretación constitucional. Revista DOXA, Alicante, n. 21, v. 2, p. 339-353, 1998. Disponível em: <https:// rua.ua.es/dspace/bitstream/10045/10369/1/doxa21-2_25.pdf > . Acesso em: 17 maio 2017.

ROTHEMBURG, Walter Claudius. Igualdade material e discriminação positiva: o princípio da isonomia. Revista Novos Estudos Jurídicos, Itajaí, n. 2, v.13, p.77-92, juldez/2008. Disponível em: <http://www.egov.ufsc.br/portal/sites/default/files/anexos/ 32745-40386-1-PB.pdf>. Acesso em: 17 maio 2017.

SARLET, Ingo Wolfgang. A eficácia dos direitos fundamentais: uma teoria geral dos direitos fundamentais na perspectiva constitucional. Porto Alegre: Livraria do Advogado Editora, 2015.

USA. Lochner v. New York. 198 U.S. 45 (1905). Joseph Lochner v. State of New York. Disponível em: <https://supreme.justia.com/cases/federal/us/198/45/case.html>. Acesso em: 30 set. 2016.

Artigo recebido em: 17/05/2017

Artigo aprovado em: 06/10/2017 